\title{
Examining Group Facilitation In Situ: The Use of Formulations in Facilitation Practice
}

\author{
L. Alberto Franco ${ }^{1,2}$ (D) Mie Femø Nielsen ${ }^{3}$
}

Received: 4 February 2017 / Accepted: 7 May 2018 / Published online: 29 May 2018

(C) The Author(s) 2018

\begin{abstract}
In this paper we examine how the talk of the facilitator shapes group workshop interactions by using the conversational object 'formulation'. The data consist of video recordings of a corpus of four facilitated workshops held with management and development teams. By adopting an exploratory video-based investigation using conversational analysis to examine our data, we highlight the significance of three distinct set of formulations used by facilitators in workshops. Specifically, our findings show how formulations that encourage reflection or facilitate action, together with those collaboratively produced, enable sense making and the achievement of a temporal conversational order among participants. This research contributes to the study of facilitated workshops by offering a more nuanced approach to the understanding of the craftsmanship of doing facilitation, its effects on the workshop process and, ultimately, workshop outcomes.
\end{abstract}

Keywords Formulations · Facilitation · Workshops · Practice · Video-based research · Conversation analysis

\section{Introduction}

Faced with the challenges resulting from increased globalisation, changing regulatory frameworks, and the quickening pace of technological development in the world today,

L. Alberto Franco

1.a.franco@1boro.ac.uk

1 School of Business and Economics, Loughborough University, Leicestershire LE11 3TU, UK

2 Pacifico Business School, Universidad del Pacifico, Lima 11, Peru

3 Department of Scandinavian Studies and Linguistics, University of Copenhagen, Njalsgade 120, 2300 Copenhagen, Denmark 
organisations increasingly rely on groups to produce novel responses to the demands imposed by these challenges. One presumed benefit of using groups is that they are able to tackle a problem more effectively than would be possible had the problem been left to any single individual. Despite their presumed benefits, however, there is substantial research evidence suggesting that groups often find working together difficult due to limited capabilities, competing interests or negative group dynamics (Kerr and Tindale 2004). The practice of facilitated workshops is one accepted and well-established approach to overcome such difficulties.

Facilitated workshops are designed to help groups engage in productive discussions that challenge shared assumptions and develop new perspectives. If effective, the work of facilitators can enable a range of group process outputs, including a full exchange and shared understanding of different views on the issues being discussed, effective communication of information from several sources, and the development of a sense of common purpose and commitment to action (Phillips and Phillips 1993). To this end, facilitators use a variety of strategies to support the group process while remaining neutral to the content of group discussions (Kaner 2007; Schuman 2005; Schwartz 2002). The question is: How does the facilitator do this? What does 'doing facilitation' look like in practice? While there is an extensive literature that characterizes facilitation in terms of the skills and knowledge required to design interventions and manage groups (e.g. Eden and Ackermann 2010; Franco and Montibeller 2010; Schuman 2005), there is a dearth of studies that draw on observations of actual facilitation practice. At the same time, there is an increasing recognition of the need to develop an in-depth understanding of the microprocesses of group decision support practice, including facilitation practice (e.g. Franco and Greiffenhagen 2018; Tavella and Franco 2015). This paper contributes to this emerging trend by realizing the opportunities afforded by video-based research based on conversation analysis to capture how facilitators go about their craft. Specifically, we show how, as group discussions proceed, facilitators 'formulate' what it is workshop participants have been saying, in order to facilitate sense making and achieve, albeit temporally, conversational order. We contend that an examination of how facilitators deploy formulations in situ is likely to produce a more nuanced understanding of how facilitation affects participants' interactions within a workshop environment, and with what conversational effects. Furthermore, we posit that such a nuanced understanding can be fed back to practice, and thus enable facilitators to become more aware of the ways in which their formulations affect the workshop process and, ultimately, the workshop outputs.

The rest of the paper is structured as follows. In the next section, we briefly review the relevant literature on facilitation and formulations. We then describe our research methodology, including our approach to data collection and analysis. After this, the results of our analysis are presented and discussed, using the presentational format that is typical of conversation analytic studies. Given the exploratory nature of this research, it is worth noting that our main concern here is with showing the significance of only a small set of formulations drawn from our data. We end the paper with some conclusions and directions for future research. 


\section{Theoretical background}

The study of facilitation is inextricably tied to the notion of a work group. Phillips and Phillips (1993) define a facilitated work group as "a small collection of people who share a goal and perform various tasks, with the help of a facilitator, to accomplish their objectives." (p. 535). From this perspective facilitation is then seen as "process in which a person whose selection is acceptable to all member of the group, is substantively neutral, and has no substantive decision-making authority diagnoses and intervenes to help a group improve how it identifies and solves problems and makes decisions, to increase the group's effectiveness" (Schwartz 2005: 21). Facilitators can be internal or external to the organization in which the work group operates, have no decision making authority, and are formally recognized by group members to assist them with the completion of their task (Wardale 2013).

The group facilitation literature has provided a plethora of frameworks that characterize the work of facilitators in terms of either competences (e.g. Azadegan and Kolfschoten 2012; Gregory and Romm 2001; Hunter and Thorpe 2005; Kaner 2007; Lieberman Baker and Fraser 2005; Schein 1999), or intervention design (e.g. Kolfschoten et al. 2007; McFadzean and Nelson 1998; Wardale 2013). Although useful, this type of frameworks gloss over the complex interactional processes by which facilitated group work is actually achieved. This is because such frameworks are mostly based on practitioners' (and academics') reflective accounts of their experience of facilitation, rather than on empirical evidence obtained from direct observation of the 'doing' of facilitation. What is lacking are in situ descriptions of facilitators doing their work. One exception within the group decision and negotiation literature are recent studies of 'facilitated group modelling', a process by which a facilitator helps a group to build a 'model' that captures a situation they are concerned with, engage in modelsupported discussions to explore the situation, and reach agreements on how to address it (Franco and Montibeller 2010; 2011). Studies in this area show the interactional and dynamic nature of facilitated modelling practices. For example, Tavella and Franco (2015) explore two sets of distinct practices, generative and calculative. The former involved communicative behaviours such as inviting, clarifying, building, affirming, and gently introducing expertise, and was associated with sharing or the creation of new knowledge by the group; the latter, on the other hand, consisted of behaviours such as challenging, reiterating and deploying authority, and it was associated with the reproduction of existing knowledge by the group. Tavella and Papadopoulos (2015) compare the work of expert and novice facilitators and, contrary to expectations, found that common facilitation practices were present in the behaviour of both experts and novices. Outside the group decision and negotiation literature, studies of facilitated workshop interactions 'as they happen' on the ground are also rare, with few exceptions. For example, Cooren et al. (2006) identify strategies used by facilitators for selecting who or what is exercising agency in an interaction sequence. Nielsen (2012) shows how a facilitator organises workshop activities, manages group-talk, and draws each group member out to participate actively in shaping a local community of practice.

Overall, these works make a contribution to further our understanding of the machinery for doing facilitation in workshops. An important part of this machinery that has 
received less attention in facilitated workshop studies is the use of formulations by facilitators. A formulation is defined as a candidate understanding of what participants have said earlier in the conversation (Garfinkel and Sacks 1970; Heritage and Watson 1979). Through the use of formulations, elements of prior talk are reintroduced, summarized, or extracting the general meaning of in a short and precise form in order to achieve confirmation, make a point, or mark what is to be seen as essential (Heritage and Watson 1979). Formulations may be used to pinpoint something, invite the interlocutor to participate in a new, shared focus and negotiate 'what we are talking about'. They often have a 'double duty' of working to achieve mutual understanding and at the same time carry out specific activities (Heritage and Watson 1979). For example, formulations are typically used in business meetings to offer 'candidate pre-closings' enabling the conclusion of a topic or the transition to new topics (Barnes 2007). In therapy and counselling, formulations are used as understanding checks or to elicit the client's personal narrative by asking questions in order to make a diagnosis (Antaki et al. 2005; Hutchby 2005; Kurri and Wahlström 2007). Formulations are also commonly used in negotiations and mediations to summarize, suggest common ground, propose solutions and conclude (Drew 2003). In summary, formulations are of special interest because, as Clifton (2009) persuasively argues, they can shape the way in which workshop participants are able to negotiate their past, present, and future interactions.

It is anticipated that formulations will be widely used in facilitated workshops. Their ability to clarify, summarize, or articulate prior talk and select elements for further treatment by the workshop participants make these conversational objects highly relevant and useful. Formulations are particularly useful during long workshops since they may serve as a vehicle to reintroduce talk that was produced earlier in the workshop and make it locally relevant (Heritage 1985). Furthermore, formulations may serve to preserve the intended neutrality of the facilitator (Eden 1990; Phillips and Phillips 1993) since they may represent a cautious response to prior talk, compared to other locally relevant responses such as assessments (Pomerantz 1984) or agreements/disagreements (Sacks 1987/1973). Finally, formulations may serve to draw inference and test hypotheses (Heritage 1985) during a workshop by means of developing prior talk in order to have it confirmed or disconfirmed by the speaker (e.g. by verbalizing something tacit, presupposed or indicated in the prior talk). The use of formulations have been studied in a variety of different institutional settings (e.g. Drew 2003). However, to our knowledge, the use of formulations has not been previously examined in facilitated workshops. In what follows we conduct a fine-grained examination of the use of formulations in facilitated workshops, with a view to develop a more nuanced understanding of the actual 'doing' of facilitation as an interactional practice.

\section{Data collection}

The data for this exploratory study was drawn from a corpus of four facilitated workshops held with management and development teams. The workshops were sponsored by senior managers of the organizations involved, and concerned with a range of 
Table 1 Workshops

\begin{tabular}{llllll}
\hline Workshop & Facilitator $(\mathrm{s})$ & Facilitation tool & Setting & Year & Location \\
\hline 1 & $\mathrm{~F}_{1}, \mathrm{~F}_{2}$ & $\begin{array}{l}\text { Group Explorer } \\
\mathrm{F}_{3}\end{array}$ & University & 2007 & UK \\
2 & $\mathrm{~F}_{3}$ & $\begin{array}{c}\text { Flip charts, pens, } \\
\text { post it notes }\end{array}$ & Business & 2012 & Denmark \\
3 & $\mathrm{~F}_{4}$ & $\begin{array}{l}\text { Goalscape } \\
\text { White board, pens, } \\
\text { post it notes }\end{array}$ & Local government & 2015 & UK \\
\hline
\end{tabular}

${ }^{1}$ Group Explorer is a mapping software developed at the University of Strathclyde by Colin Eden and Fran Ackermann

${ }^{2}$ Goalscape is a visual goal setting software sold by Goalscape Software GmbH

issues involving strategy, innovation, or change. All workshops were videotaped and audio-recorded, which roughly translated into a total of $30 \mathrm{~h}$ of facilitated workshop interactions that were initially transcribed verbatim. General information about the workshops can be found in Table 1.

From this larger pool of data, and for reasons of clarity and space limitations, we will be showing in the findings section extracts from one setting only (Workshop 1). This was a six-hour facilitated workshop commissioned by the corporate development division of a British university in the Midlands region, ${ }^{1}$ and was held as part of the division's strategic review of external income generation. The aim of the division is to coordinate the generation of external income for the university through consultancy, knowledge transfer partnerships, and training. In 2007, the division was facing the challenge of meeting aspirational targets regarding the university's external income. A facilitation team of two people was brought into run the workshop. The workshop participants included the head of the division and six business development managers. The overall purpose of the workshop was to achieve a shared understanding of the key strategic issues that the division was facing at the time concerning the generation of external income.

The particular tool used by the facilitation team to do their work was a strategy map created with Group Explorer, a networked computer system that uses a visual causal mapping technique to support decision making in teams (Bryson et al. 2004; Eden and Ackermann 2010). The map was used by the workshop participants to capture a range of strategic issues and their perceived implications. To construct the map, participants assembled in the workshop room and sat at small tables arranged in a horseshoe-shaped layout, with a console laptop for each table. The consoles were connected to a master laptop operated by the lead facilitator, who used it to control the consoles and assemble the team's contributions, and then displayed them on a large public screen located at the front of the workshop room. The screen was visible to all participants and provided a focal point around which group discussions about strategic issues took place. Participants' contributions were gathered both anonymously through

\footnotetext{
1 The name of the university and the identities of workshop participants have all been disguised for confidentiality purposes.
} 

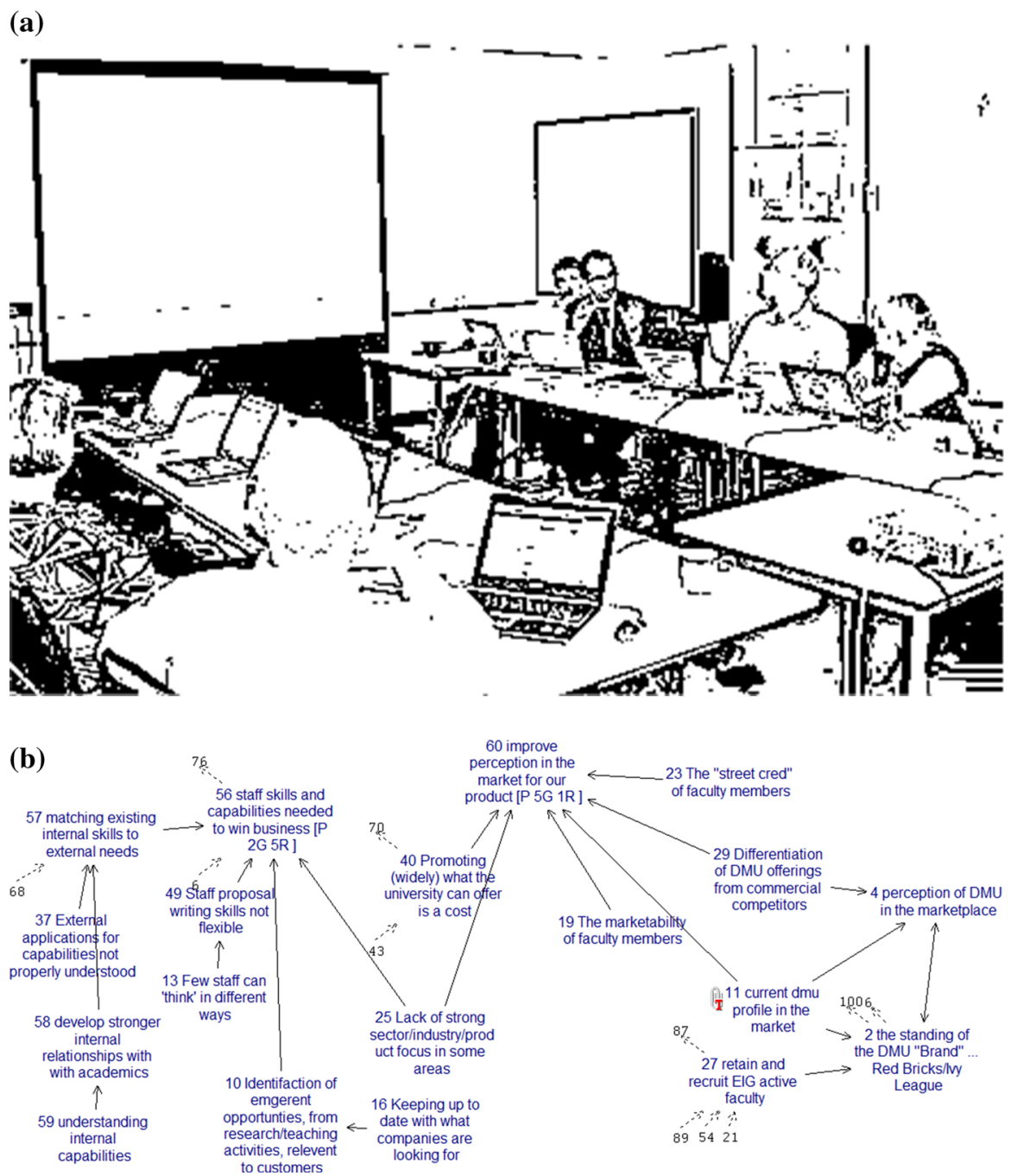

Fig. 1 a University workshop setting (front angle). b Excerpt from strategy map produced in the university workshop

the consoles and quickly displayed on the screen as they were entered, and via the content facilitator. In addition, and assisted by the second facilitator, participants jointly structured their contributions to create the strategy map. The workshop setting, together with an excerpt of the strategy map built during the workshop, is shown in Fig. 1a, b.

The workshop process was divided into six planned group activities undertaken in a linear sequence and guided by the facilitation team: (1) gathering issues; (2) linking and exploring issues; (3) articulating the system of goals implied by the issues; (4) prioritizing the issues; (5) developing options to address the issues; and (6) prioritizing options and reaching agreements about action. In what follows we present three inter- 
action segments from this workshop to illustrate the different types of formulations observed in our data. Names of the organization, persons and activities/work areas, which may convey or reveal any specific identities, have all been rendered anonymous.

\section{Data analysis}

Data analysis followed an iterative-inductive approach that required cycling back and forth between theory and data (Orton 1997). First, we watched and listened to the recorded data with the extra benefit of having verbatim transcripts, and noted instances of any potentially interesting conversational exchanges between the facilitator and the participants in the sequential conduct of the workshops. One noticing was the range of formulations that facilitators regularly used to open, manage, and close defined workshop activities such as gathering, structuring, or evaluating participants' contributions. To make the process of identifying formulations systematic, we followed Heritage and Watson's (1979) distinction between formulations that extract the general meaning of the preceding talk (or 'gist'), and formulations that draw out its relevant implication (or 'upshot'). The basic format embodied by these formulations is that of a conversational adjacency pair, with the first part involving a preface (e.g. 'so...') or syntactic frame (e.g. 'are you saying that...'), and the second part showing confirmation or disconfirmation. Next, we selected shorter segments containing these formulations, so that their nature and constitutive features could be examined closely. These shorter segments were then re-transcribed according to the Jefferson's notation system (Jefferson 2004).

Finally, we analyzed the data from a multimodal conversation analytic perspective, incorporating the participants' use of a range of resources from different semiotic fields in order to produce social actions and create meaning (Goodwin 1981, 1994, 2003, 2007; Goodwin and Goodwin 1996; Sidnell 2005; Stivers and Sidnell 2005; Streeck 1993). Specifically, our analysis drew on a range of analytical concepts from conversation analysis and linguistics. For example, the notion that linguistic interactions are used by interlocutors to accomplish new social orders is a core concept (e.g. Antaki and Widdicombe 1998; Atkinson and Heritage 1984). To illustrate, a participant may suggest the need for "attracting external funding", and the action of suggestion produces a turn-at-talk local identity for the participants as 'suggester of attracting external funding'. Moreover, it creates reciprocal identities for co-participants as 'receivers of suggestions', or 'evaluators of suggestions' or even 'participants in need of attracting external funding'. Another core concept is intersubjectivity, which in conversation analytic terms refers to the interactional practices used by participants to show each other their local understandings of what is going on in the conversation (Schegloff 1992; Schegloff and Sacks 1973). By responding to a turn-at-talk, a next speaker shows the first speaker how she/he perceived the prior turn (e.g., if the suggestion of a new theme is welcomed or treated as a distraction). Moreover, by responding to the response, the first speaker shows his/her understanding of the second turn, and if the second turn evidences a correct hearing of the first turn. This intersubjectivity also serves to show the researcher if the speakers share tacit as-sump-tions or if they initiate repair (Sche- 
gloff 1991; Schegloff et al. 1977). Therefore, this next-turn-proof-procedure (Drew 1992), and the ability to presuppose what is implied in the talk (Harder 1980; Vagle et al. 1994), make it possible to identify partici-pant orientations towards norms and values, as well as non-questionable, acceptable actions.

\section{Findings}

In this section we present the three types of formulations identified within our dataset: formulations that encourage reflection; formulations that facilitate action; and collaboratively-produced formulations. These formulations correspond highly with previous studies of formulations in other institutional settings (e.g. Drew 2003). Furthermore, the three types of formulations identified were relevant to particular stages of a workshop. Typically, workshops have three identifiable stages: an opening stage where expectations are set and a roadmap of the workshop process is introduced; a middle stage of sorting something out which is related to the purpose of the workshop (e.g., decision making, idea development); and a closing stage. This staged structure is in accordance with studies of other institutional settings (e.g. Hutchby 1996; Ten Have 1999). Specific workshops designs may consist of multiple stages, but comparable are the basic three-part structure of opening, sorting out and closing. Our findings relate to last two stages of a workshop.

As already stated, the formulations shown below were derived from our corpus of four workshops, though for reasons of clarity and space we are showing extracts from one setting only (Group Explorer workshop -see Table 1).

\subsection{Encouraging reflection formulations}

The type of formulation presented here was regularly seen in the 'sorting' stage of a workshop, where we see lots of clarifications, hypotheses and challenges made in order to explore mutual understandings and seek common ground. Below we show a formulation used by the facilitator (Sandro) to encourage the group to reflect further on the basis of the preceding talk, as illustrated below. In the following segment, the participants have been talking extensively about the problem of getting researchers to work harder at attracting external funding to the university. (For an explanation of the symbols used in the transcribed examples, see the appendix) (Figs. 2, 3 and 4). 


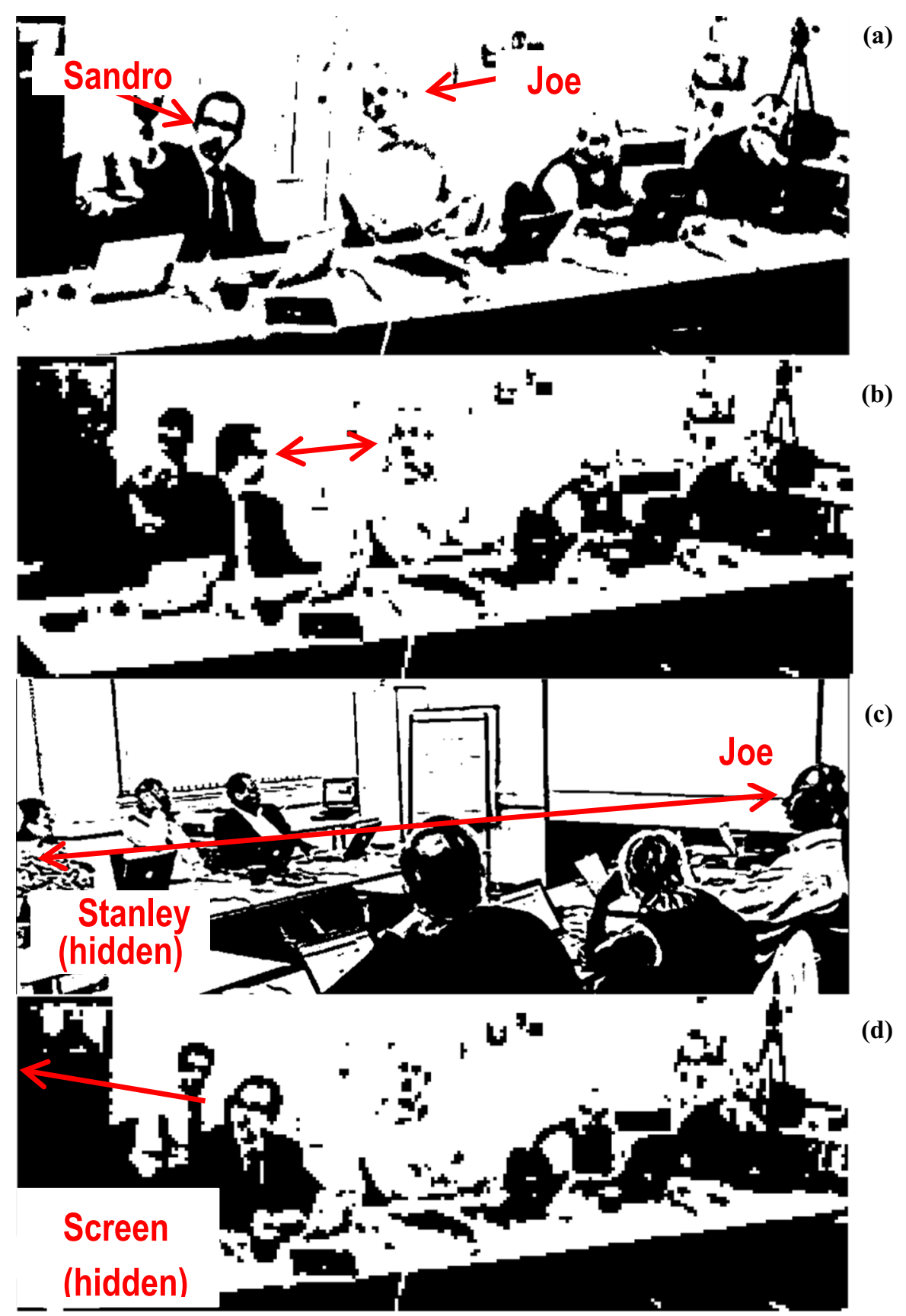

Fig. 2 So... when you say...how does that relate to...? 


\section{Example 1: So...when you say...how does that relate to...?}

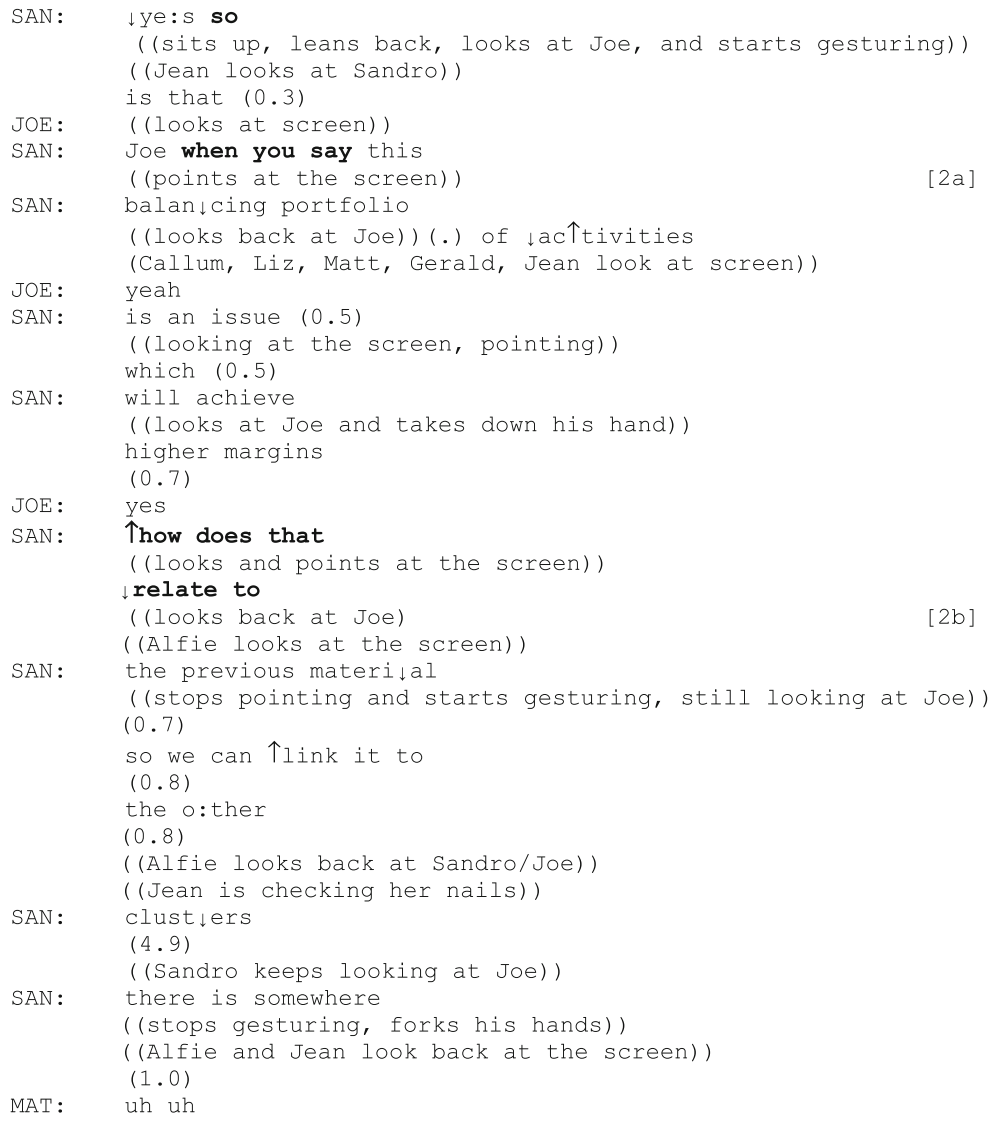


The facilitator's formulation “ $\downarrow$ ye:s so is that $(0.3)$ Joe when you say this balan $\downarrow$ cing portfolio (.) of $\downarrow$ ac $\uparrow$ tivities is an issue (0.5) which (0.5) will achieve higher margins (0.7) $\uparrow$ how does that $\downarrow$ relate to the previous materi $\downarrow$ al" (lines 1-25) has the so-prefaced design 'so when you say $X$ how does that relate to $Y$ '. He selects Joe as next speaker by his gaze (lines $2,9,16,23,25$ ), accomplishes using the screen as a mutual point of reference (lines $5,7,13,21$ ). At possible completion points in constructing the turn, he gets a confirmation from Joe (lines 11, 19). Joe does not respond at the transition relevant place (line 25), instead there is a pause (line 27), and that leads Sandro to extend his turn by producing an account (line 28 ) and produce a new response point. Joe still does not respond, and a pause occurs (line 29). Then Sandro produces an incremental turn (lines 30-34) and there is a very long pause (line 35). Sandro produces yet another response point (line 37) and there is yet another pause (line 40). Matt now self-selects (line 41) but drops out, and after another pause (line 46) Sandro begins a turn that may be designed to resolve the matter by suggesting something (line 47). At that point Stanley first, and then Joe, respond; the latter with a suggestion of a link (line 49), designed as a tentative proposal. Sandro follows up on Joe's suggestion by asking for clarification (line 52) and receives a confirmation from Callum and Joe (lines 53, 54).

The function of the formulation in the above segment (lines 1-25) is to identify the gist of prior talk, focus on something new and encourage the participants to reflect further. By continuously producing new response points and enduring several pauses, he forces the group to come up with something. The turn is left hanging in the air, and a particular participant is left with the floor until somebody else comes into rescue him. He addresses a particular participant and narrows the invited contribution down to a very specific point to make, connecting a prior turn of his (lines 6-8) to something hitherto left hanging (line 25).

\subsection{Action-oriented formulations}

Our second category consists of formulations that are commonly observed in the closing stage of the workshop, and which are used for reaching a conclusion or proposing a solution. In the segment below, we see the participants as a group committing to future actions that will be executed after the workshop. 


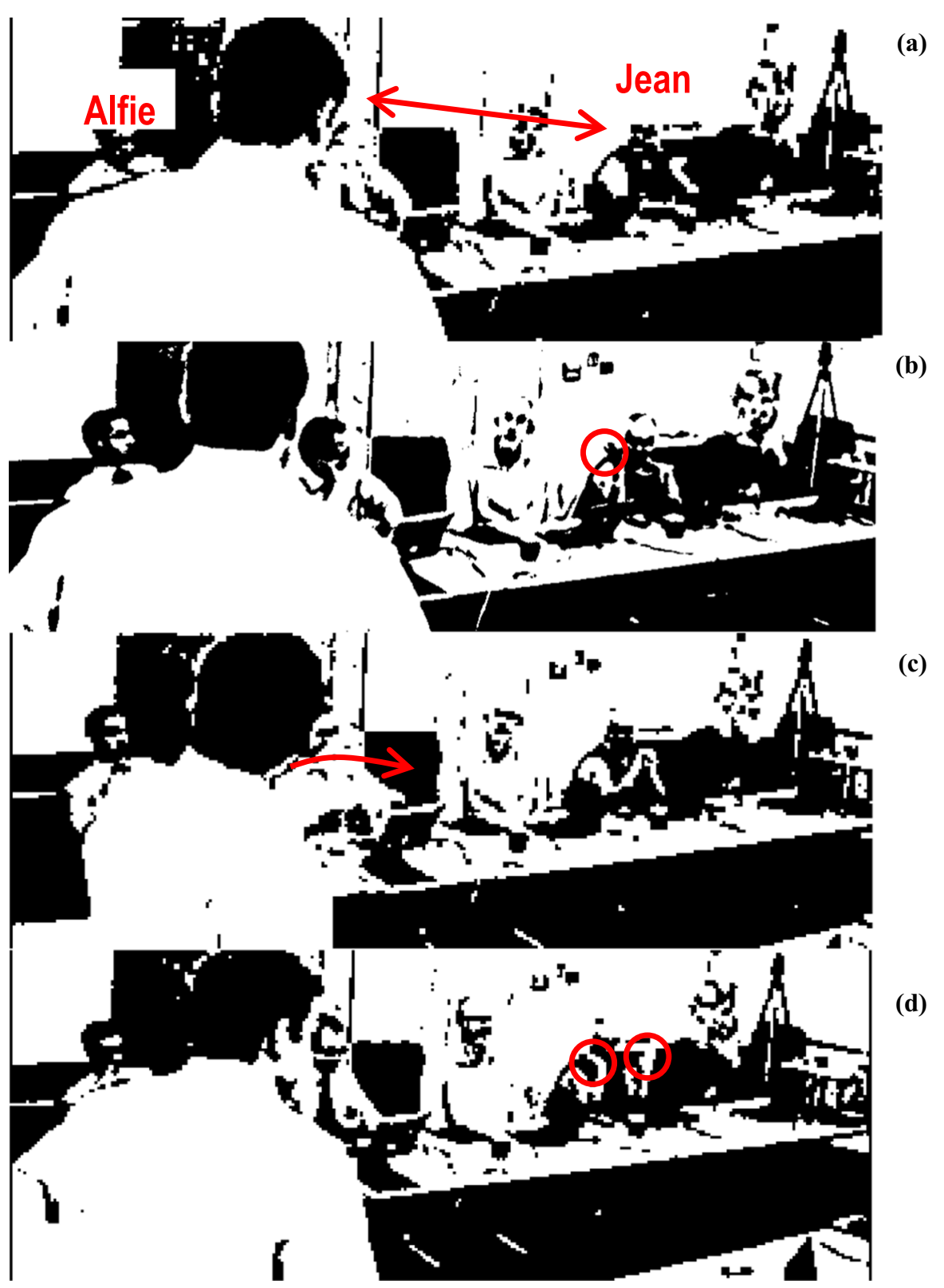

Fig. 3 So you're saying you'll do it..? 
Example 2: So you're saying you'll do it..?"

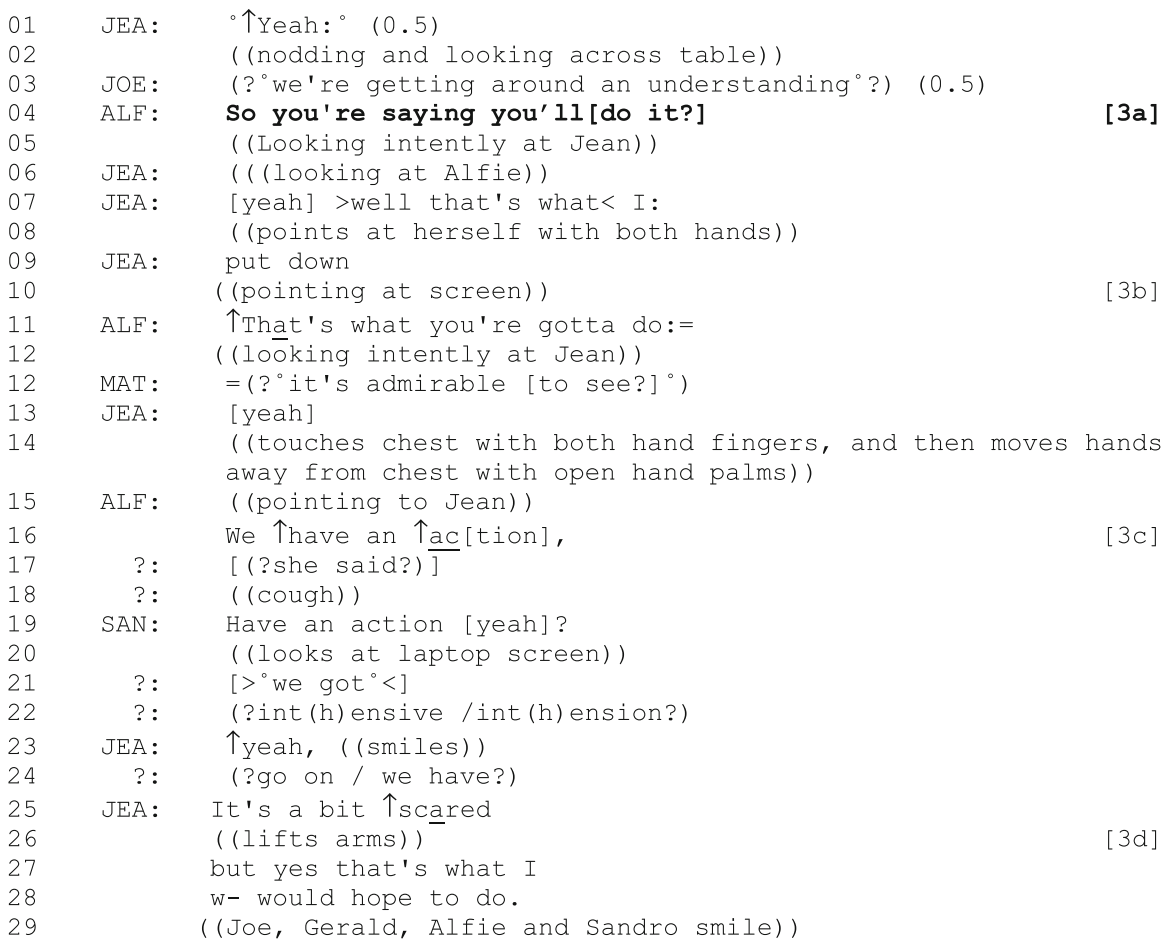

After a sequence in which Joe has highlighted the attractiveness of the proposal to engage with academics in the exploration of their areas of interest, Jean confirms quietly while nodding (line 2), and Joe seems to be saying something along the lines of "we're getting around to an understanding", but his turn is almost inaudible. At this point, the (second) facilitator Alfie asks for confirmation ("So you're saying you'll do it?" line 4) while especially looking to Jean for uptake. This is yet another formulation, here formulating other's future actions as an upshot of the preceding talk. Jean now gazes back at Alfie and confirms "yeah> well that's what <I: put down" the action in question (lines 7-9). Alfie recycles his attempt to achieve confirmation (line 11), again addressing Jean with his gaze, and getting her to confirm it (line 12). After that exchange, Alfie points to Jean and says "We $\uparrow$ have an $\uparrow$ action" (lines 15-16). Alfie is pointing to Jean (with a large wave shaped movement ending in a downward pointing direction) while insistently gazing at the other facilitator (Sandro), as if to say "you should make a record of that". By means of that gesture he is making Jean accountable for the commitment to future action and at the same time telling Sandro to make a record of it. Sandro recycles the action formulation with an almost identical repetition ("Have an action yeah?" line 19), which Jean confirms with a smile (line 23 ) and modifies (line 27) to something that she'll "would hope to do" (line 28) even if "a bit $\uparrow$ scared" is her description of the situation. The action formulation in line 16 serves to announce an outcome, and the formulation in line 19 seeks confirmation of that announcement. 
This sequence of formulating the conclusion as an upshot (lines 4, 11), achieving agreement or confirmation (lines 7-9, 12, 23 27, 28), and confirming the agreement with another action formulation (line 19) is similar to exchanges seen in other institutional settings, such as general practice consultations where the doctor orients to confirming the patient's agreement with the recommended action (Gafaranga and Britten 2004).

\subsection{Collaboratively produced formulations}

The phenomenon of one speaker completing another speaker's turn in progress is termed 'collaborative completion' (Sacks 1992) or 'co-participant completion' (Lerner 1991). By means of this practice the speaker may propose a candidate understanding of the turn in progress. We have identified this type of phenomenon across both the sorting out and the closing stages of a workshop, in what we called 'collaboratively produced formulations'. It can be a formulation used by the facilitator to present a hypothesis as an upshot of the group's preceding talk, which is a very common use of formulations in workshops, but this variant is designed to be collaboratively completed by workshop participants. This is illustrated in the following segment.

Example 3: "An issue which is..."

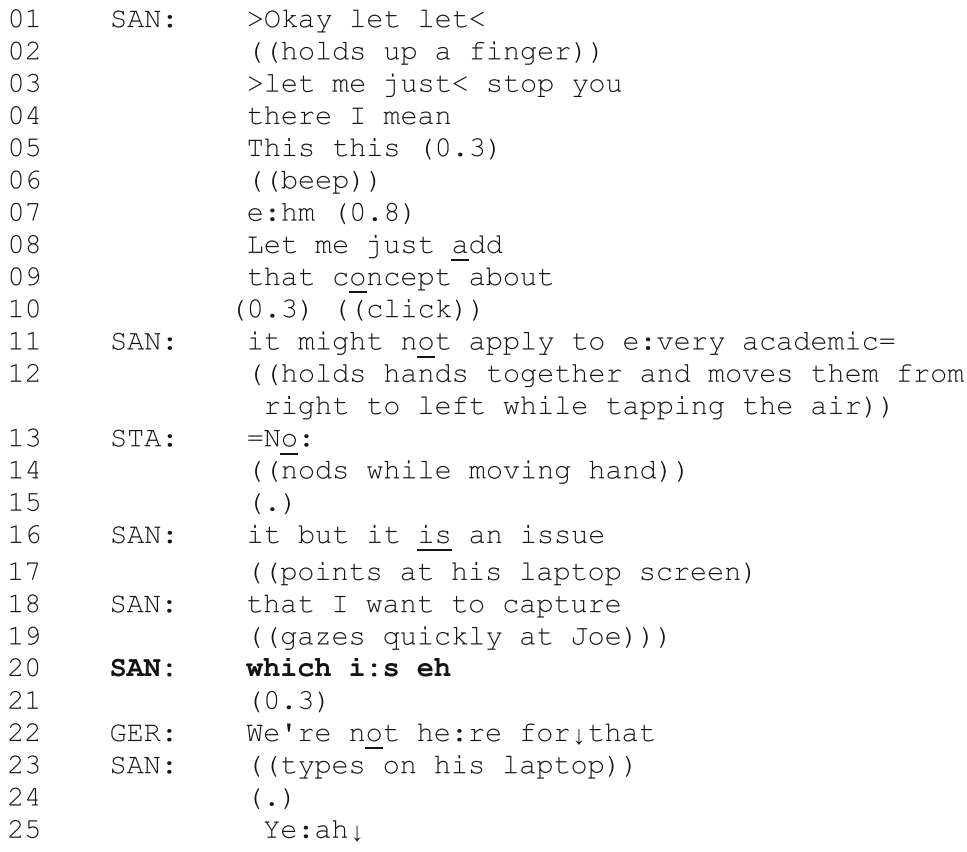




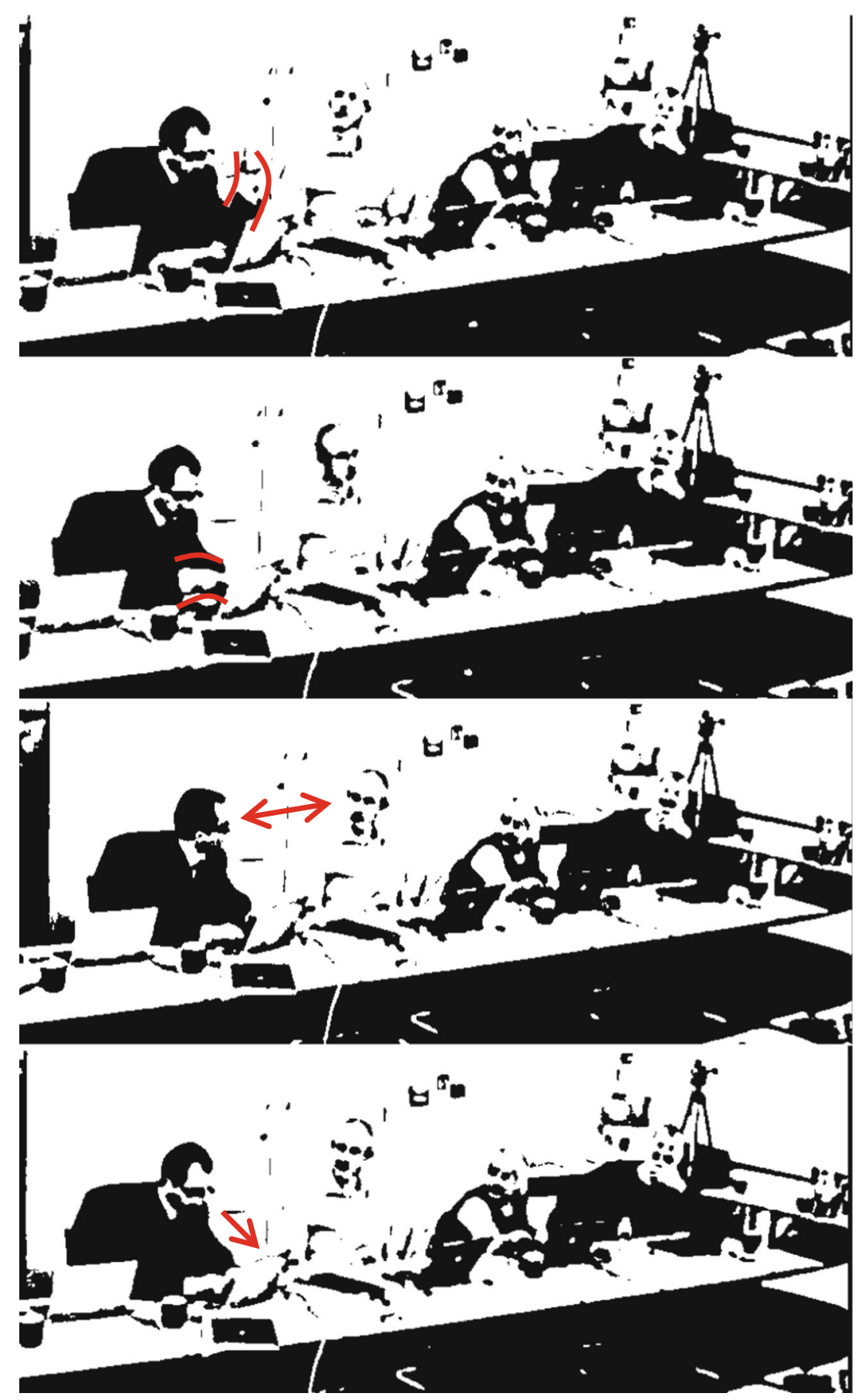

(a)

Fig. 4 [An issue] which is...? 
The facilitator begins his turn by marking it not as an uptake to the immediately preceding talk (lines 1-8) but something that he wants to say in spite of that. He marks his contribution as an addition to a known concept ("that concept" line 9), which he specifies verbally (line 11) and non-verbally (line 12). Stanley confirms the relevance of the topic by nodding and uttering a stressed and prolonged "No:" (line 13) that is linking to Sandro's negative utterance design ("might not apply" line 11), which is an almost identical repetition of a previous turn produced by Stanley. Then he eagerly produces an account for making the contribution (note the gesture and gaze, lines 17, 19). There is a lot of preparation done by Sandro : misplacement marking, redesigning and accounting twice (lines 1-19). Then Gerald comes in with the punch line "We're not he:re for $\downarrow$ that" (line 22), which Sandro confirms (line 25). The facilitator is by means of the formulation presenting a hypothesis that is designed as building on preceding talk ("that concept about") and marked as an attempt to "capture" an "issue" from their preceding discussion. The formulation "that concept about (0.3) it might not apply to e:very academic (.) it but it is an issue that I want to capture which i:s eh (0.3) We're not he:re for $\downarrow$ that" is collaboratively produced by Sandro and Gerald.

Note, that Gerald's collaborative completion is not unwarranted. Sandro makes an effort to produce talk that the participants will confirm or collaboratively complete; his turn is designedly incomplete, making a completion of it a relevant action for coparticipants. Besides the mentioned work, he also stretches the sound on "is", adds a hesitation marker and pauses (lines 20,21). He is creating the optimal conditions for a participant to come in with the climax of his turn, leaving himself a response turn in the next turn, confirming what he has been fishing for. Collaboratively completed formulations may be considered extreme versions of formulations aimed at achieving confirmations from co-participants.

\section{Discussion and conclusion}

The exploratory video-based investigation reported in this paper provides a complimentary departure from the mainstream group facilitation literature that has emphasized the use of facilitator competences and intervention design frameworks to study and guide the practice of facilitation. For example, prescriptions such as 'active listening', 'maintain a task orientation' or 'handing back contritions in changed form' (Ackermann 1996; Franco and Montibeller 2010; Phillips and Phillips 1993) do not take into account the different ways in which such actions can be enacted in workshops. Similarly, workshop 'scripts' (e.g. Ackermann et al. 2011; Hovmand et al. 2012) or 'ThinkLets' (e.g. Azadegan and Kolfschoten 2012; Kolfschoten et al. 2007) that provide detailed instructions to facilitators on what to say to the group in order to achieve intended workshop outputs, do not consider the different ways in which such instructions can be applied in interaction. By contrast, our exploratory study shows how formulations are used to achieve some of the complex interactional work involved in enacting and sustaining these general and more specific prescriptions.

When the facilitator produces a formulation by presenting a hypothesis, projecting an action, or proposing a conclusion, a significant amount of interactional work is 
involved to achieve a confirmation from the participants. Specifically, the facilitator is putting forward to the group something that they need to make sense of, either looking backwards, as in the clarification of previous talk; or looking forward, as in thinking further, building on previous talk. Furthermore, we note that facilitators use what is known as 'so-prefacing' (Heritage 1985) to mark the beginning of a formulation turn design. By using such 'so'-prefaced upshots facilitators make evident what action is due, and from whom it is due (cf. Raymond 2004).

We see formulations being produced by the facilitator throughout the whole workshop. Typically, a facilitator's question may lead to further questions or a discussion, after which the facilitator produces a formulation in order to make sense of prior talk co-produced by multiple participants. A facilitator's formulation is mainly designed to achieve a confirmation from the participants, but it can also revitalize the discussion leading to the facilitator recycling and/or producing a new formulation until a sequence of formulation-confirmation is achieved. Therefore, formulations both serve as a tool in the process of ongoing talk and as an aid in achieving the goal of the interaction.

A key requirement of effective facilitation is to support a group process without influencing the content of group discussions (Kaner 2007; Schuman 2005; Schwartz 2002). Our findings show how facilitators use formulations to draw out the participants' contributions on their behalf without influencing content. By using formulations, facilitators draw out contributions from different participants, one at a time, or leave the floor open for all. Furthermore, they decide when to deliver contributions on behalf of the group and when to foster the group to deliver their own contributions (e.g. "we are not here for that", Example 3, line 22).

Formulations, however, are not to be seen as verbal phenomena alone. As our empirical material demonstrates, formulations are also embodied social actions. For example, the evidence suggests that the physical act of pointing may be doing similar interactional work as the use of 'so' as a preface to a formulation, the embodied 'soprefacing'. To illustrate, when the second facilitator, Alfie, points to the participant, Jean, and says "we have an action" (Example 2, line 16), we see his bodily movement of pointing as an embodied equivalent to 'so-prefacing'. Pointing gestures are embodied actions that may be used by participants to point to something, somewhere or someone, and are typically described to be a referential gesture that cannot be understood when looked upon in isolation (Auer and Bauer 2011; Clark 2003; Haviland 2000; Klippi 2015; Streeck 2009). Gestures like pointing are not separate actions, but a situated interactive activity, which may establish a particular physical space as a shared focus for the organization of cognition and action (Goodwin 2003).

By adopting a conversation analytic approach to examine our video recordings, we were able to provide a fine-grained analysis of the use and interactional impacts of three different types of formulations used by the facilitator. First, our analysis shows that formulations encouraging participants' reflections require a significant amount of interactional work on the part of the facilitator, who puts forward to the group something that they need to make sense of, either by looking backwards, as in the clarification of previous talk; or by looking forward, as in thinking further, building on previous talk. Second, we show how in collaboratively produced formulations the facilitator actively directs the group talk, taking and redesigning his turns so that the participants can both predict where he is going, and able to produce the completion 
by themselves. Third, our findings suggest that action formulations can either project participants' future activities (e.g. “you're saying you'll do it?”), or announce participants' commitment to a particular course of action (e.g. "we have an action plan"). In both cases we see action formulations as an upshot of the preceding talk. In addition, the empirical material presented here demonstrates that formulations produced in situ are embodied social actions in which body movements may be doing similar interactional work as verbal communication. Taken together, our fine-grained analysis offers a more nuanced approach to the understanding of the embodied craftsmanship of doing facilitation.

Our research has at least two obvious limitations. Firstly, to develop an in-depth understanding of the significance of formulations in situ, we had to focus on only a small set of formulations. Secondly, while we did not distinguish between the facilitators for analytical purposes, we do acknowledge that the personality and style of the facilitator can play a significant in workshop interactions. Notwithstanding these limitations, there is considerable potential for further research into the practice of facilitated workshops using the conversation analytic perspective adopted here. One possible direction would be to undertake further fine-grained analysis of our data, with a view to identify formulations that might be distinct from those discussed in this paper. Another possible avenue for further research would be to study if facilitators use more tendentious formulations in processes where they were hired to pursue a specific agenda. An additional, and potentially useful, future study might involve comparing different facilitation tasks and workshop protocols with the actual, interactional practices of the facilitators when supporting the group process.

Finally, our study also has practical implications for the work of facilitation practitioners. Specifically, our findings can contribute towards the development of a 'tool kit' of formulations available for doing facilitation. Indeed a more detailed understanding of the use of different formulations and their interactional consequences would be a useful part of any repertoire of facilitation skills. Furthermore, the development of training materials based on actual use of formulations such as those identified in this research, rather than on the use of role plays or workshop design 'scripts' (e.g. Andersen and Richardson 1997; Hovmand et al. 2012) and 'ThinkLets' (e.g. Kolfschoten et al. 2006, 2011) in a simulated environment, could offer would-be or practicing facilitators the opportunity to rehearse the interactions that would comprise an actual workshop episode and to assess what participants would do in the situation (e.g. Stokoe 2013). However, this development would require a larger sample of facilitated workshops from which to develop such training materials.

Acknowledgments Thanks are due to our workshop participants without whom this study would not have been possible.

Open Access This article is distributed under the terms of the Creative Commons Attribution 4.0 International License (http://creativecommons.org/licenses/by/4.0/), which permits unrestricted use, distribution, and reproduction in any medium, provided you give appropriate credit to the original author(s) and the source, provide a link to the Creative Commons license, and indicate if changes were made. 


\section{Appendix: Transcription notation}

\begin{tabular}{|c|c|c|}
\hline Symbol & Explanation & Meaning \\
\hline , & Comma & Global intonation is continuing \\
\hline$\cdot$ & Period after word or syllable & Global intonation is final \\
\hline$?$ & Question mark & Global intonation is rising \\
\hline i & Inverted question mark & $\begin{array}{l}\text { Global intonation is slightly } \\
\text { rising }\end{array}$ \\
\hline$\underline{\text { meaning }}$ & Underlining & Stress \\
\hline : & Colon & Stretched sound \\
\hline$\uparrow$ & Upward arrow & $\begin{array}{l}\text { Upward local intonation } \\
\text { movement, pitch reset from } \\
\text { low }\end{array}$ \\
\hline$\downarrow$ & Downward arrow & $\begin{array}{l}\text { Downward local intonation } \\
\text { movement }\end{array}$ \\
\hline (.) & Period in brackets & Micro pause, less than $0.2 \mathrm{~s}$ \\
\hline$(0.7)$ & Number in brackets & Pause, measured in seconds \\
\hline §meaning§ & & Pronounced carefully \\
\hline$»$ meaning « & & Talking fast \\
\hline[ & & Overlapping talk begins \\
\hline ] & & Overlapping talk ends \\
\hline "meaning & & Smile voice \\
\hline- & Dash & Cutoff \\
\hline. $\mathrm{h}$ & Period before $h$ & Inbreath \\
\hline h & & Outbreath \\
\hline (h) & $\mathrm{h}$ in brackets & $\begin{array}{l}\text { Explosive outbreath, like when } \\
\text { laughing }\end{array}$ \\
\hline$\circ$ & & Low volume \\
\hline$\circ$ & & Very low volume \\
\hline MEANING & & High volume \\
\hline$=$ & & $\begin{array}{l}\text { The turn or turn constructional } \\
\text { unit is latched on prior } \\
\text { turn/turn constructional unit }\end{array}$ \\
\hline
\end{tabular}

\section{References}

Ackermann F (1996) Participant's perceptions on the role of facilitators using group decision support systems. Group Decis Negot 5(1):93-112

Ackermann F, Andersen DF, Eden C, Richardson GP (2011) ScriptsMap: a tool for designing multi-method policy-making workshops. Omega 39:427-434

Andersen DF, Richardson G (1997) Scripts for group model building. Syst Dyn Rev 13(2):107-129

Antaki C, Widdicombe S (1998) Identities in talk. Sage, London

Antaki C, Barnes R, Leudar I (2005) Diagnostic formulations in psychotherapy. Discourse Stud 7:627-647

Atkinson JM, Heritage J (1984) Structures of social action: studies in conversation analysis. Cambridge University Press, Cambridge 
Auer P, Bauer A (2011) Multimodality in aphasic conversation: why gestures sometimes do not help. J Interact Res Commun Disord 2(2):231-259

Azadegan A, Kolfschoten G (2012) An assessment framework for practicing facilitator. Group Decis Negotiat 23:1-33

Barnes R (2007) Formulations and the facilitation of common agreement in meetings talk. Text Talk-An Interdiscip J Lang Discourse Commun Stud 27(3):273-296

Bryson JM, Ackermann F, Eden C, Finn CB (2004) Visible thinking: unlocking causal mapping for practical business results. Wiley, Chichester

Clark HH (2003) Pointing and placing. In: Kita S (ed) Pointing: where language, culture, and cognition meet. Lawrence Erlbaum, Mahwah, pp 243-268

Clifton J (2009) 'Doing' influence and making decisions in management team meetings. J Bus Commun 46:57-79

Cooren F, Thompson F, Canestraro D, Bodor T (2006) From agency to structure: analysis of an episode in a facilitation process. Hum Relat 59(4):533-565

Drew P (1992) Contested evidence in courtroom cross-examination: the case of a trial for rape. In: Drew P, Heritage $\mathbf{J}$ (eds) Talk at work: interaction in institutional settings. Cambridge University Press, Cambridge

Drew P (2003) Comparative analysis of talk-in-interaction in different institutional settings: a sketch. In: Glenn P, LeBaron CDL, Mandelbaum J (eds) Studies in language and social interaction in honor of Robert Hopper. Lawrence Erlbaum, Mahweh, pp 293-308

Eden C (1990) The unfolding nature of group decision support: two dimensions of skill. In: Eden C, Radford J (eds) Tackling strategic problems: the role of group decision support. Sage, London, pp 48-52

Eden C, Ackermann F (2010) Decision making in groups: theory and practice. In: Nutt PC, Wilson DC (eds) Handbook of decision making. Wiley-Blackwell, Chichester, pp 231-272

Franco LA, Greiffenhagen C (2018) Making OR practice visible: using ethnomethodology to analyse faciltated modelling workshops. Eur J Oper Res 265(2):673-684

Franco LA, Montibeller G (2010) Facilitated modelling in operational research. Eur J Oper Res 205(3):489-500

Franco LA, Montibeller G (2011) 'On-the-Spot' modelling and analysis: the facilitated modelling approach. In: Cochran JJ, Cox LA Jr, Keskinocak P, Kharoufeh JP, Smith JC (eds) Wiley Encyclopedia of operations research and management science. Wiley, New York

Gafaranga J, Britten N (2004) Formulation in general practice consultations. Text 24:147-170

Garfinkel H, Sacks H (1970) On formal structures of practical actions. In: McKinney JC, Tiryakian EA (eds) Theoretical sociology: perspectives and development. Appleton-Century-Crofts, New York, pp $337-366$

Goodwin C (1981) Conversational organization: interaction between speakers and hearers. Academic Press, New York

Goodwin C (1994) Professional vision. Am Anthropol 96:606-633

Goodwin C (ed) (2003) Conversation and brain damage. Oxford University Press, Oxford

Goodwin C (2007) Participation, stance and affect in the organization of activities. Discourse Soc 18(1):53-74

Goodwin C, Goodwin MH (1996) Seeing as situated activity: Formulating planes. In: Engeström Y, Middleton DA (eds) Cognition and communication at work. Cambridge University Press, Cambridge, pp 61-95

Gregory WJ, Romm NR (2001) Critical facilitation: learning through intervention in group processes. Manag Learn 32(4):453-467

Harder P (1980) Møveri. In: Harder P, Poulsen A (eds) Hvad går vi ud fra? Om forudsætninger i sprog og handling. København, Gyldendals Sprogbibliotek

Haviland JB (2000) Pointing, gesture spaces, and mental maps. In: McNeill D (ed) Language and gesture. Cambridge University Press, Cambridge, pp 13-46

Heritage JC (1985) Analyzing news interviews: aspects of the production of talk for an overhearing audience. In: Van Dijk TA (ed) Handbook of discourse analysis, vol 3. Academic Press, London, pp 95-116

Heritage JC, Watson DR (1979) Formulations as conversational objects. In: Psathas G (ed) Everyday language: studies in ethnomethodology. Irvington Press, New York, pp 123-162

Hovmand PS, Andersen DF, Rouwette E, Richardson GP, Rux K, Calhoun A (2012) Group model-building 'scripts' as a collaborative planning tool. Syst Res Behav Sci 29(2):179-193 
Hunter D, Thorpe S (2005) Facilitator values and ethics. In: Schuman SP (ed) The IAF handbook of group facilitation: best practices from the leading organization in facilitation. Jossey-Bass, San Francisco, pp 545-558

Hutchby I (1996) Confrontation talk: arguments, asymmetries, and power on talk radio. Lawrence Earlbaum, Mahwah

Hutchby I (2005) 'Active listening": formulations and the elicitation of feelings-talk in child counselling. Res Lang Soc Interact 38:303-329

Jefferson G (2004) Glossary of transcript symbols with an introduction. In: Lerner GH (ed) Conversation analysis: studies from the first generation. John Benjamin, Amsterdam, pp 13-31

Kaner S (2007) Facilitator's guide to participatory decision making, 2nd edn. Jossey-Bass, San Francisco

Kerr NL, Tindale RS (2004) Group performance and decision making. Annu Rev Psychol 55(1):623-655

Klippi A (2015) Pointing as an embodied practice in aphasic interaction. Aphasiology 29(3):337-354

Kolfschoten GL, Briggs RO, de Vreede GJ, Jacobs PHM, Appelman JH (2006) Conceptual foundation of the ThinkLet concept for collaboration engineering. Int J Human Comput Stud 64(7):611-621

Kolfschoten GL, Hengst-Bruggeling M, De Vreede G-J (2007) Issues in the design of facilitated collaboration processes. Group Decis Negot 16(4):347-361

Kolfschoten GL, De Vreede G-J, Pietron LR (2011) A training approach for the transition of repeatable collaboration processes to practitioners. Group Decis Negot 20(3):347-371

Kurri K, Wahlström J (2007) Reformulations of agentless talk in psychotherapy. Text Talk 27:315-338

Lerner GH (1991) On the syntax of sentences-in-progress. Lang Soc 20:441-458

Lieberman Baker L, Fraser C (2005) Facilitator core competencies as defined by the International Association of Facilitators. In: Schuman SP (ed) The IAF handbook of group facilitation: best practices from the leading organization in facilitation. Jossey-Bass, San Francisco, pp 459-472

McFadzean E, Nelson T (1998) Facilitating problem-solving groups: a conceptual model. Leadersh Org Dev J 19(1):6-13

Nielsen MF (2012) Using artifacts in brainstorming sessions to secure participation and decouple sequentiality. Discourse Stud 14(1):87-109

Orton JD (1997) From inductive to iterative grounded theory: zipping the gap between process theory and process data. Scand J Manag 13:419-438

Phillips LD, Phillips MC (1993) Facilitated work groups: theory and practice. J Oper Res Soc 44(6):533-549

Pomerantz AM (1984) Agreeing and disagreeing with assessments: Some features of preferred/dispreferred turn shapes. In: Atkinson JM, Heritage J (eds) Structures of social action: studies in conversation analysis. Cambridge University Press, Cambridge, pp 57-101

Raymond G (2004) Prompting action: the stand-alone "so" in ordinary conversation. Res Lang Soc Interact 37(2):185-218

Sacks, H. 1987/1973. On the preference for agreement and contiguity in sequences in conversation. In: Button G, Lee JR (eds) Talk and social organization. Multilingual Matters, Clevedon

Sacks H (1992) Lectures on conversation (edited by Gail Jefferson). Basil Blackwell, Oxford

Schegloff EA (1991) Conversation analysis and socially shared cognition. In: Resnick L, Levine JM, Teasley SD (eds) Perspectives on socially shared cognition. American Psychological Association, Washington, $\mathrm{DC}$

Schegloff EA (1992) Repair after next turn: the last structurally provided defense of intersubjectivity in conversation. Am J Sociol 97(5):1295-1345

Schegloff EA, Sacks H (1973) Opening up closings. Semiotica 8(4):289-327

Schegloff EA, Jefferson G, Sacks H (1977) The preference for self-correction in the organization of repair for conversation. Language 53:361-382

Schein EH (1999) The concept of 'client' from a process consultation perspective: a guide for change agents. J Org Change Manag 10(3):202-216

Schuman SP (ed) (2005) The IAF handbook of group facilitation: best practices from the leading organization in facilitation. Jossey-Bass, San Francisco

Schwartz R (2002) The skilled facilitator: a comprehensive resource for consultants, facilitators, managers, trainers, and coaches. Jossey-Bass, San Francisco

Schwartz R (2005) The skilled facilitator approach. In: Schuman S (ed) The IAF handbook of group facilitation: best practices from the leading organization in facilitation. Jossey-Bass, San Francisco, pp 21-34

Sidnell J (2005) Multimodal interaction. Mouton de Gruyter, Berlin

Stivers T, Sidnell J (2005) Introduction: multimodal interaction. Semiotica 156(1/4):1-20 
Stokoe E (2013) The (in)authenticity of simulated talk: comparing role-played and actual conversation and the implications for communication training. Res Lang Soc Interact 46(2):1-21

Streeck J (1993) Gesture as communication I: its coordination with gaze and speech. Commun Monogr 60:275-299

Streeck J (2009) Forward-gesturing. Discourse Process 46(2-3):161-179

Tavella E, Franco LA (2015) Dynamics of group knowledge production in facilitated modelling workshops: an exploratory study. Group Decis Negot 24(3):451-475

Tavella E, Papadopoulos T (2015) Expert and novice facilitated modelling: a case of a Viable System Model workshop in a local food network. J Oper Res Soc 66(2):247-264

Ten Have P (1999) Doing conversation analysis: a practical guide. Sage, London

Vagle W, Sandvik M, Svennevig J (1994) Tekst og kontekst. En innføring i tekstlingvistikk og pragmatikk. J.W. Cappelens Forlag, Oslo

Wardale D (2013) Towards a model of effective group facilitation. Leadersh Org Dev J 34(2):112-129 